\title{
Information Technology-Based Management of Clinically Healthy COVID-19 Patients: Lessons From a Living and Treatment Support Center Operated by Seoul National University Hospital
}

Ye Seul Bae ${ }^{1,2}$, MD, MPH; Kyung Hwan Kim ${ }^{1,3,4}$, MD, PhD; Sae Won Choi ${ }^{1,5}$, MD; Taehoon $\mathrm{Ko}^{1}$, PhD; Chang Wook Jeong ${ }^{1,6}$, MD, PhD; BeLong Cho ${ }^{2,7}$, MD, MPH, PhD; Min Sun Kim ${ }^{7,8}$, MD; EunKyo Kang ${ }^{2,7}$, MD

${ }^{1}$ Office of Hospital Information, Seoul National University Hospital, Seoul, Republic of Korea

${ }^{2}$ Department of Family Medicine, Seoul National University Hospital, Seoul, Republic of Korea

${ }^{3}$ Department of Thoracic and Cardiovascular Surgery, Seoul National University Hospital, Seoul, Republic of Korea

${ }^{4}$ Department of Thoracic and Cardiovascular Surgery, Seoul National University College of Medicine, Seoul, Republic of Korea

${ }^{5}$ Department of Emergency Medicine, Seoul National University Hospital, Seoul, Republic of Korea

${ }^{6}$ Department of Urology, Seoul National University Hospital, Seoul, Republic of Korea

${ }^{7}$ Department of Public Health and Medical Service, Seoul National University Hospital, Seoul, Republic of Korea

${ }^{8}$ Department of Pediatrics, Seoul National University Hospital, Seoul, Republic of Korea

\section{Corresponding Author:}

Kyung Hwan Kim, MD, PhD

Office of Hospital Information

Seoul National University Hospital

101 Daehak-ro, Jongno-gu

Seoul, 03080

Republic of Korea

Phone: 82220727600

Fax: 82220727600

Email: kkh726@snu.ac.kr

\section{Abstract}

Background: South Korea took preemptive action against coronavirus disease (COVID-19) by implementing extensive testing, thorough epidemiological investigation, strict social distancing, and rapid treatment of patients according to disease severity. The Korean government entrusted large-scale hospitals with the operation of living and treatment support centers (LTSCs) for the management for clinically healthy COVID-19 patients.

Objective: The aim of this paper is to introduce our experience implementing information and communications technology (ICT)-based remote patient management systems at a COVID-19 LTSC.

Methods: We adopted new electronic health record templates, hospital information system (HIS) dashboards, cloud-based medical image sharing, a mobile app, and smart vital sign monitoring devices.

Results: Enhancements were made to the HIS to assist in the workflow and care of patients in the LTSC. A dashboard was created for the medical staff to view the vital signs and symptoms of all patients. Patients used a mobile app to consult with their physician or nurse, answer questionnaires, and input self-measured vital signs; the results were uploaded to the hospital information system in real time. Cloud-based image sharing enabled interoperability between medical institutions. Korea's strategy of aggressive mitigation has "flattened the curve" of the rate of infection. A multidisciplinary approach was integral to develop systems supporting patient care and management at the living and treatment support center as quickly as possible.

Conclusions: Faced with a novel infectious disease, we describe the implementation and experience of applying an ICT-based patient management system in the LTSC affiliated with Seoul National University Hospital. ICT-based tools and applications are increasingly important in health care, and we hope that our experience will provide insight into future technology-based infectious disease responses.

(J Med Internet Res 2020;22(6):e19938) doi: 10.2196/19938 


\section{KEYWORDS}

COVID-19; clinical informatics; mobile app; telemedicine; hospital information system; app; health information technology

\section{Introduction}

The coronavirus disease (COVID-19) pandemic has become a major concern worldwide since the first report from Wuhan, China in December 2019 [1-4]. According to the World Health Organization, up to 4 million patients and 277,000 deaths have been reported [5,6]. In South Korea, the first confirmed case of COVID-19 was diagnosed on January 20, 2020; as of May 10, 2020, 10,874 patients have been diagnosed, 9610 have been released from isolation, and 256 have died [7].

South Korea has earned recognition worldwide for its tackling of the pandemic. The number of infections dropped from 900 a day in late February to less than 20 per day in late April. South Korea acted preemptively against COVID-19 with robust testing, vigorous tracing, strict social distancing, and rapid treatment of patients according to severity. In late February, a super-spreader, "Patient 31," caused a regional outbreak in the southern city of Daegu and Gyeongsangbuk Province by attending religious services. Health authorities conducted contact tracing and decided to test every close contact irrespective of whether they showed any symptoms [8]. Up to $80 \%$ of patients tested were clinically healthy, and due to the substantial number of tests performed, medical institutions were highly saturated. To provide appropriate treatment and to reduce the burden on the medical institutions of Daegu and Gyeongsangbuk Province, the government established a new treatment system based on severity on March 1, 2020 [9]. Every patient was classified based on severity into mild, moderate, severe, or extremely severe cases. Patients identified as moderate, severe, and extremely severe were immediately hospitalized for treatment $[9,10]$.

Asymptomatic patients testing positive for COVID-19 and mild symptomatic patients were isolated and accommodated at government-sponsored facilities called living and treatment support centers (LTSCs) to be monitored by health care staff at least twice a day [9]. Patients can be discharged from the LTSC after two consecutive negative tests. In case of emergencies, patients are transferred to nearby hospitals [9]. The government asked several tertiary hospitals to operate LTSCs. The first LTSC opened in Daegu; Seoul National University Hospital (SNUH) opened the third LTSC at the SNUH Human Resource Development Center in Mungyeong, Gyeongsangbuk Province, 180 kilometers southeast of Seoul and 100 kilometers northwest of Daegu.

In this study, we introduce the experience of operating a LTSC for the management of mild COVID-19 patients and introducing information and communications technology (ICT)-based solutions tailored to the characteristics of the patients' clinical pathways.

\section{Methods}

We implemented new electronic health record (EHR) templates for the hospital information system (HIS), dashboards, an electronic prescription (e-prescription) system, and cloud-based medical image sharing. A newly developed mobile app enabled effective and accurate communication between health care providers and patients, and wearable vital sign monitoring devices facilitated management of clinically healthy COVID-19 patients.

\section{The SNUH HIS}

SNUH is a non-profit, academic referral government hospital with 1778 beds. SNUH treats approximately 600,000 inpatients and 2.3 million outpatients per year and employs about 1400 physicians and 2200 nurses. SNUH internally developed a computerized physician order entry system in 1999, implemented a picture archiving and communication system (PACS) in 2001, and started using an EMR in 2004. In 2001, SNUH's internal information technology (IT) department was spun off as a separate company, ezCaretech, which is now the largest HIS company in Korea [11]. The current version of the HIS, BESTCare 2.0, which integrates and manages all services needed by the hospital, was built by ezCaretech and implemented in 2016. The HIS was modified to support the LTSC.

\section{Patient Management Systems to Support a LTSC in Mungyeong}

Health authorities screened and designated clinically healthy COVID-19 patients to be admitted to LTSCs; however, patient management was entirely the responsibility of the entrusted hospital. Patients were considered clinically healthy if their vital signs were stable (blood pressure, heart rate, and oxygen saturation within normal limits), if they were afebrile, and if they were asymptomatic or had mild COVID-19 symptoms. Clinical health status was determined by directly evaluating the patient at the time of diagnosis. Blood pressure monitors, pulse oximeters, and thermometers were placed in each room for the patient to measure their blood pressure, oxygen saturation, and temperature. In some rooms, a wearable continuous vital sign monitoring device was placed alongside conventional devices for continuous remote monitoring. To protect the medical staff, exposure was minimized via the use of remote communication methods and self-monitoring by the patients.

\section{User Survey}

We conducted online surveys to measure satisfaction with the systems modified for the LTSCs. Three separate online surveys were conducted: patient satisfaction with the mobile app, patient satisfaction with the wearable device, and satisfaction of the medical staff. Only participants who voluntarily agreed to participate were included. Responses were measured using a 5-point Likert scale. The questionnaires were administered using an online survey form. Participants accessed questionnaires via a URL and were able to complete the survey at any time or place. The study was approved by the Institutional Review Board of SNUH (IRB number: H-2004-026-1115). The ethics committee waived the need for informed participant consent. 


\section{Results}

\section{Patient Management in the LTSC}

Patients who were positive for the COVID-19 real time polymerase-chain reaction (RT-PCR) test but were asymptomatic or had mild symptoms were subject to LTSC admission. Upon disease confirmation, a group of experts from public authorities triaged the patient and determined treatment depending on the severity of the patient's symptoms. Patients with severe symptoms were hospitalized and treated in negative pressure isolation units, and mild and asymptomatic patients were designated to be admitted to LTSCs [7-9]. Patients were initially admitted to the LTSC from self-isolation in their homes or were transferred from other local hospitals.

As of April 20, 2020, a total of 18 LTSCs were operational in Korea. 2948 patients were admitted to the centers, of whom 155 were transferred to another hospital due to worsening symptoms [12]. Because the number of newly diagnosed patients decreased and the number of people who were released from quarantine increased, the 18 LTSCs were consolidated into 5 centers in May 2020.

The SNUH facility in Mungyeong was originally constructed as a human resource development center used to train SNUH personnel. It was not a medical facility and therefore did not contain any medical equipment. After the decision was made to adapt the facility at Mungyeong into a LTSC, the necessary equipment, including personal computers, monitors, a portable chest $\mathrm{x}$-ray machine, medical devices, and the hospital network, was installed in 2 days. Since the LTSC opened on March 5, 2020, a total of 118 patients have been admitted.

Figure 1 shows the overall flow of ICT operations according to the patient journey. A cloud system was used for instant medical image sharing in cases of patient transfer. Patients self-reported vital signs and subjective symptoms through a mobile app. These data were automatically linked to the newly introduced semistructured EHR template for mild COVID-19 patients in the HIS to help the medical staff obtain patient-reported data conveniently and accurately. In addition, in some rooms equipped with wearable devices, vital signs were transmitted to the HIS in real time. Through the mobile app, medical staff were able to notify and alert individual patients and communicate with them when needed. The Korean government temporarily permitted virtual patient management to minimize COVID-19 transmission on February 22, 2020 [7]. Each patient self-measured vital signs and reported symptoms through the mobile app at 9:00 AM and 4:30 PM every day, and they spoke with the nurse in charge via remote video consult twice a day from 9 AM-12 PM and 5 PM-8 PM and once a day with a physician in Seoul. If the patient had a concern or problem, the assigned nurse could be contacted by text or telephone. To respond to emergencies, more than two medical staff members (physicians or nurses) were always present in the patient center at Mungyeong.

Figure 1. Overall ICT operation flow according to the patient's journey. EHR, electronic health record. ICT: information and communications technology. Q\&A: question and answer. SNUH: Seoul National University Hospital.

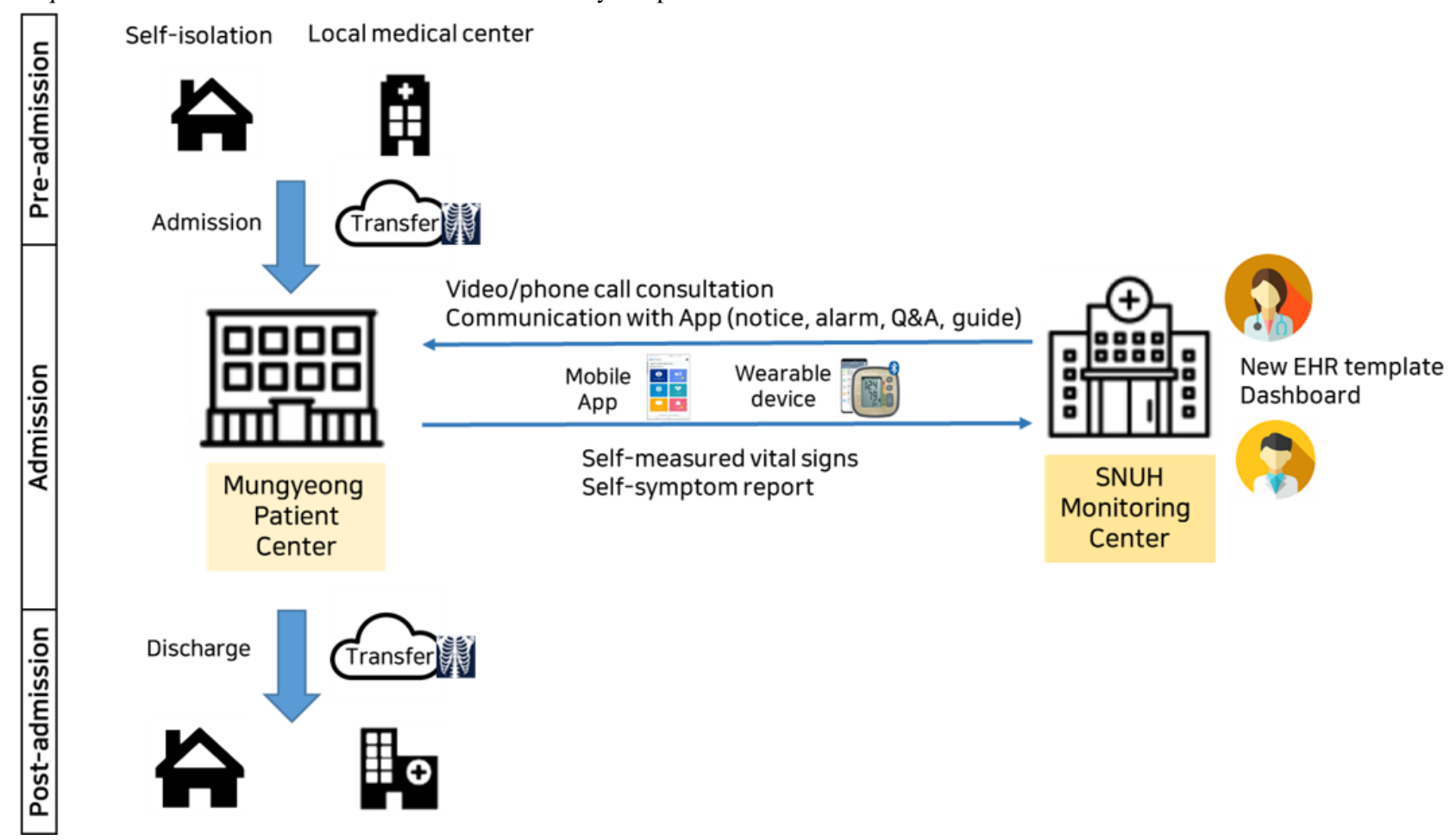

Patients were discharged if they had two consecutive negative COVID-19 tests. The RT-PCR test used by SNUH is the STANDARD M nCov Real-Time Detection Kit (SD Biosensor), which was issued an emergency use authorization by the United States Food and Drug Administration and the Korea Food and
Drug Administration. The sensitivity of the test is $100 \%$ and the specificity is greater than $97 \%[13,14]$. Chest $\mathrm{X}$-rays were performed periodically to check for progression to pneumonia after admission [7-9]. 
The Korean government funded the operation of the LTSCs through reimbursement of medical fees. The conditions for reimbursement were as follows: medical personnel are dispatched to the LTSC, patients are seen twice a day, and necessary medical equipment, such as an X-ray machine, is available. The fee of about US $\$ 30$ per patient per day could be claimed if the conditions were met [15].

\section{Enhancements to the HIS}

A multidisciplinary task force of physicians, nurses, infection specialists, epidemiologists, and IT experts headed by the chief information officer of the hospital was convened to direct and manage the modifications to the IT systems to support the LTSC. First, we customized and enhanced our HIS to support the LTSC.

\section{New EHR Templates and Order Codes}

To use the SNUH HIS in the LTSC, a hospital network was installed in addition to the usual internet service. An LTSC department was established in the HIS for efficient and independent patient management. Only chest X-rays and RT-PCR using a nasopharyngeal swab or sputum samples were performed at the LTSC; new order codes were created for these tests. Moreover, we developed three new EHR templates for admission, progression, and discharge, which were used to track the symptoms and general status of the patients (Figure 2). The EHR templates for the LTSCs were constructed in a semistructured form that combined a free text section for medical staff to freely record observations during consultation and a structured form that was configured to include patients' subjective respiratory, gastrointestinal, and psychological symptoms, objective vital signs, previous medical history, contact history of COVID-19, and allergies. When a patient entered self-reported symptoms or vital signs on the mobile app, the data were automatically linked to the EHR template to be viewed during remote video consultation.

Figure 2. Modified EHR template for daily consultation at the LTSC.

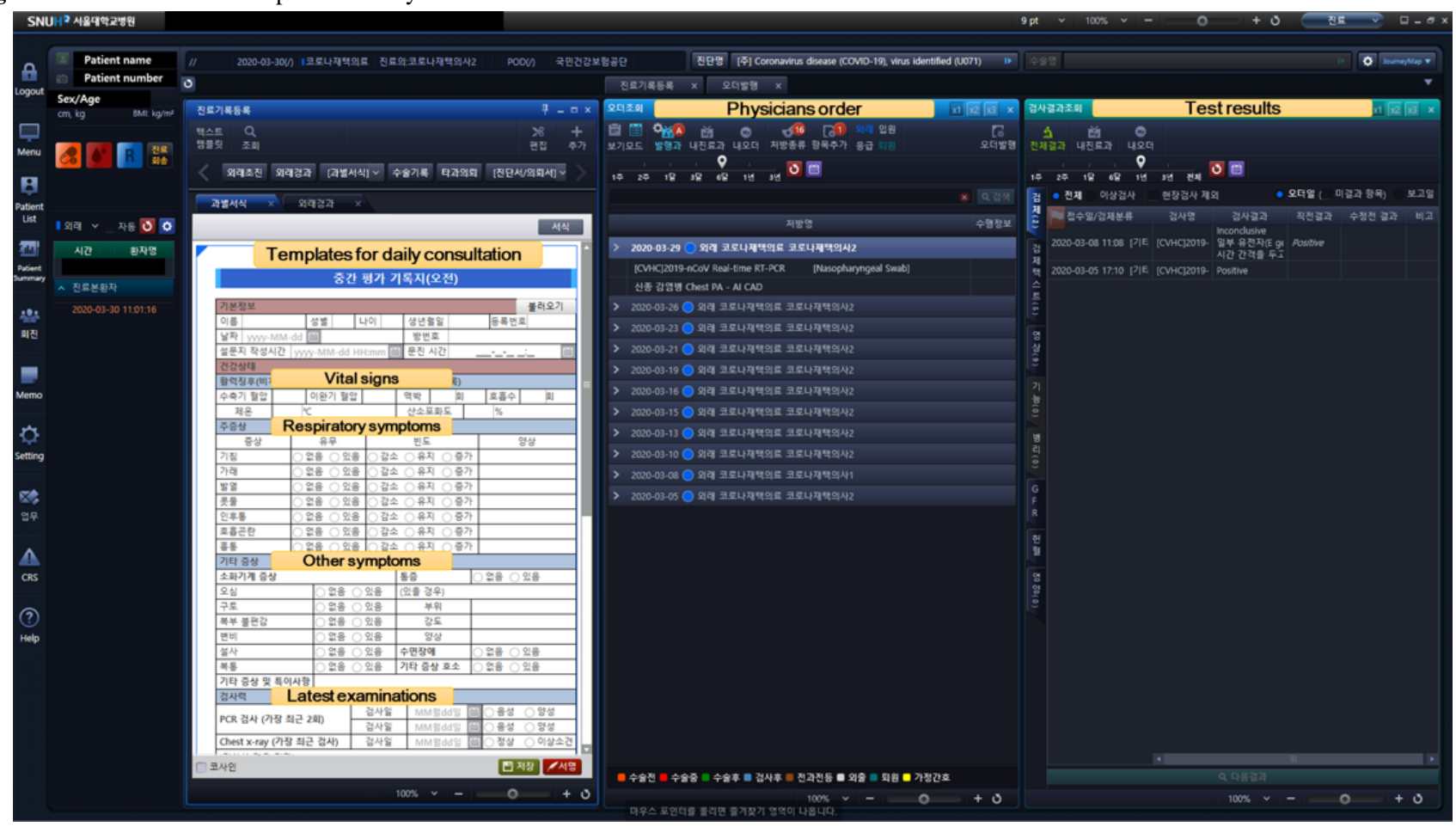

\section{Dashboard}

A dashboard for the medical staff was developed to display real time information for all patients at central monitoring centers at Seoul and Mungyeong. The dashboard displayed each patient's vital signs (heart rate, body temperature, respiratory rate, blood oxygen saturation) and information on whether the patient has any symptoms or chest x-ray abnormalities (Figure 3). 
Figure 3. Dashboard of the EHR displaying real time information for patients at the LTSC.

\begin{tabular}{|c|c|c|c|c|c|c|c|c|c|c|c|}
\hline \multirow{2}{*}{ 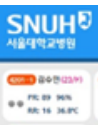 } & \multicolumn{3}{|c|}{ 생활치료센터 현황판 } & \multicolumn{2}{|c|}{$17: 22$} & & \multicolumn{3}{|c|}{ 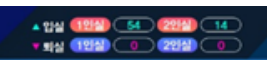 } & \multicolumn{2}{|c|}{ 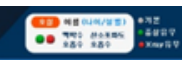 } \\
\hline & 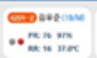 & 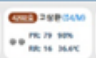 & 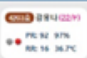 & 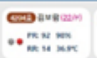 & 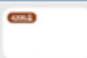 & 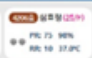 & 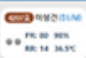 & $\infty$ & 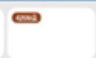 & 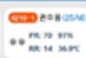 & 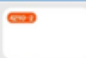 \\
\hline 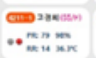 & cid & 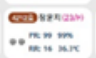 & $\mathrm{cm}$ & 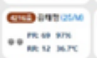 & m & $\infty$ & 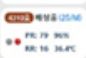 & $\infty$ & $\infty$ & 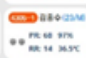 & 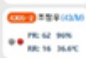 \\
\hline 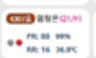 & 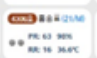 & 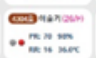 & $\mathrm{m}$ & 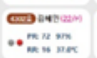 & 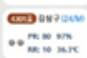 & 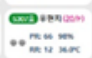 & 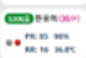 & 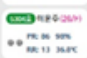 & $\infty$ & 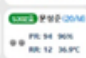 & 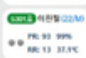 \\
\hline 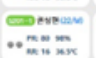 & 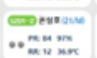 & 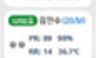 & 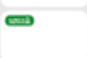 & 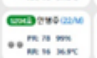 & 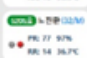 & $\infty$ & 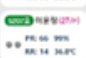 & 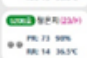 & 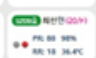 & 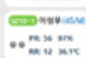 & 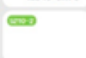 \\
\hline en & $\mathrm{Cm}$ & 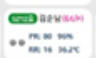 & $\mathrm{cm}$ & 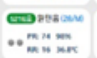 & 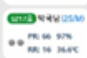 & 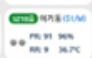 & 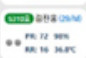 & 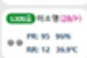 & 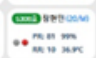 & 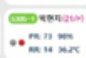 & 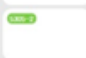 \\
\hline 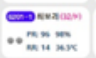 & 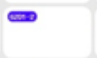 & 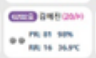 & $\mathrm{cm}$ & 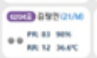 & 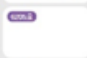 & 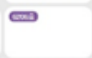 & 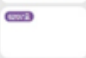 & 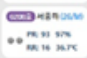 & 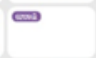 & 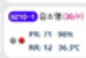 & 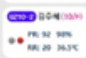 \\
\hline Cind & $\mathrm{CII}$ & $\infty$ & $\mathrm{cm}$ & 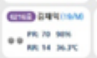 & 西 & 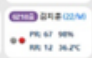 & 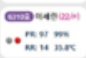 & 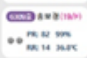 & 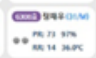 & 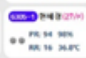 & $\Leftrightarrow$ \\
\hline 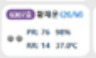 & 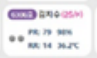 & 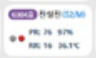 & 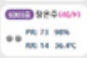 & 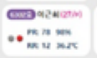 & 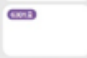 & $\omega$ & 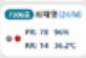 & $\lim _{\text {소네 }}$ & $\mathbb{m}_{48 y x}$ & $\lim _{48 n \pi}$ & $\lim _{\text {쇼에 }}$ \\
\hline 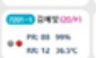 & 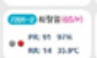 & $\infty_{* 4}$ & $\mathrm{~m}$ & 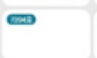 & 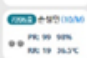 & 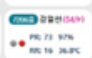 & $\infty$ & 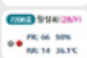 & 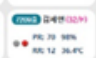 & 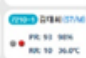 & 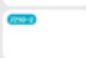 \\
\hline 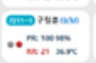 & तis & 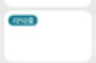 & 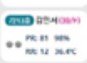 & 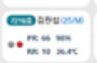 & 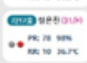 & $\omega$ & 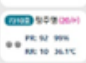 & 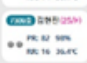 & $\infty$ & 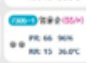 & 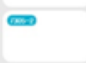 \\
\hline
\end{tabular}

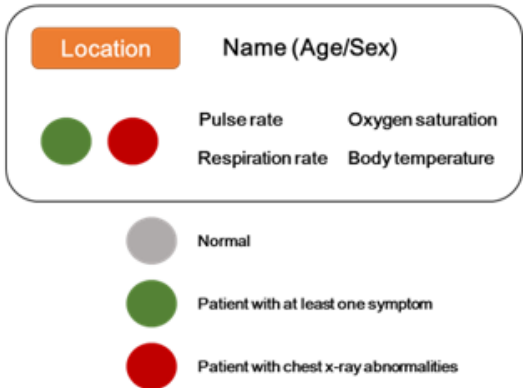

\section{e-Prescription System}

Basic medications were prepared at SNUH and transported to the LTSC facility. Plans were made for sourcing other medications from local pharmacies by sending prescriptions electronically. A mobile app-based e-prescription system was added to the SNUH app for patients on March 1, 2020. The patient could send the prescription information through the app to a nearby pharmacy selected by the user. There were two cases of e-prescription system usage in the LTSC. A 25-year-old female patient taking propranolol regularly for palpitation was admitted but did not bring the medication with her. During the stay, she complained of palpitations with tachycardia. The physician at the central monitoring center in Seoul prescribed propranolol, and the prescription was electronically sent through the app to a local pharmacy about $1.8 \mathrm{~km}$ from the LTSC. Another case was a 25-year-old male patient with hyperthyroidism who was prescribed and received methimazole using the e-prescription system.

\section{Cloud-Based Medical Image Sharing}

Seamless medical image interoperability is not available in Korea. Generally, medical images are copied to CDs and carried by the patient from one institution to another. Clearly, this process is inadvisable due to the nature of the disease. In addition, SNUH decided to review the chest $\mathrm{x}$-ray and computerized tomography images taken by radiologists at SNUH before a to the LTSC. Also, producing a CD copy for patients in need of transfer to another hospital due to emergent or worsening conditions was not practical. Thus, we decided to establish a simple cloud-based system for instant and effective medical image sharing (Figure 4). Users from other hospitals would upload the patient's medical images to the cloud, which were then transferred to the SNUH PACS for physician review. All medical images were shared using the Digital Imaging and Communications in Medicine (DICOM) format. Twelve patients used this system when they were admitted. Two patients who had no symptoms at the time of admission developed difficulty breathing and were transferred to a nearby hospital. Chest x-rays taken at LTSC were quickly shared with medical staff in the receiving hospital using this system.

Figure 4. The cloud-based medical image sharing platform. PACS: picture archiving and communication system. SNUH: Seoul National University Hospital.

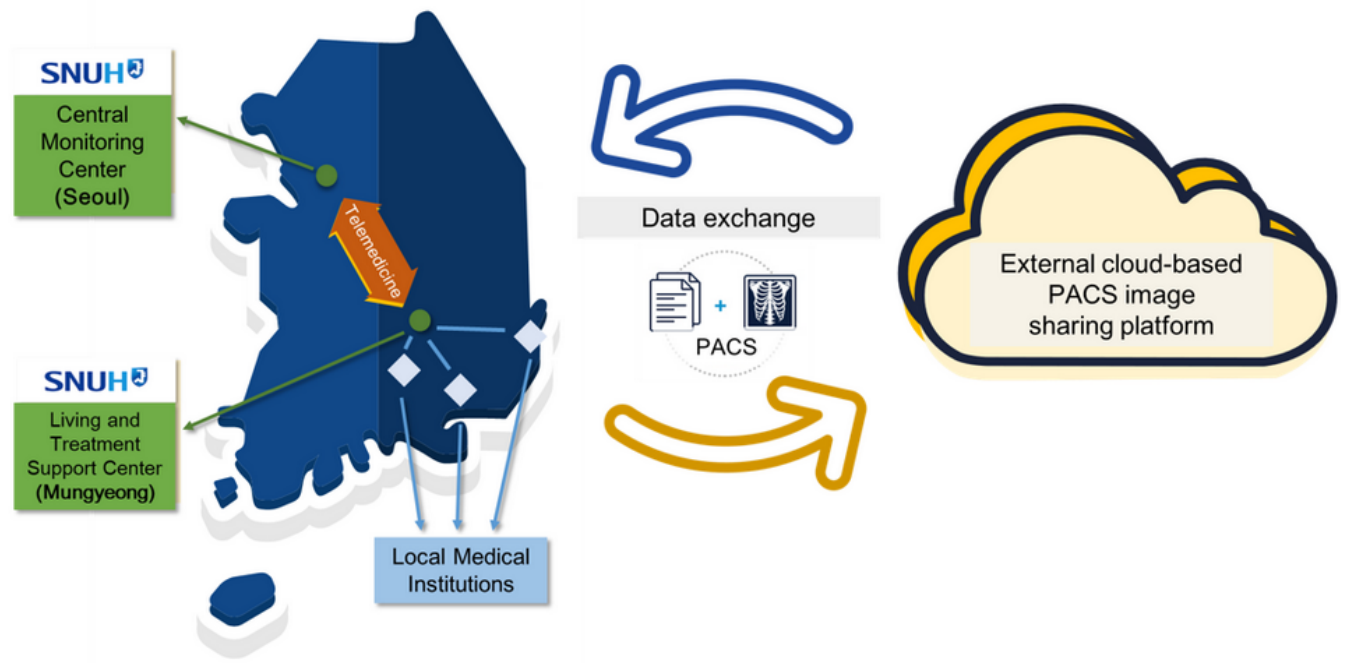




\section{Wearable Vital Sign Monitoring Device}

Some patients were asked to use a wearable device to measure their vital signs and enable the medical staff to monitor them remotely. The Vital-sign Data Recorder (VDR-1000) from Tribell Labs is a wearable medical multi-function measurement device that can be easily used by patients (Multimedia Appendix 1). It can directly measure the patient's electrocardiogram, pulse rate, blood oxygen saturation, respiratory waveform, respiratory rate, and body temperature. The measured data are transmitted to the central monitoring system (CMS) using Wi-Fi and are then forwarded to the HIS. Medical staff in Mungyeong and Seoul can monitor vital signs of patients using both the CMS monitor and HIS (Multimedia Appendix 2). The CMS software can set alarms with different thresholds for each patient. An alarm sounds when a value outside the threshold range is measured, assisting the medical staff to respond quickly (Multimedia Appendix 3).

\section{Mobile App}

To enable efficient patient management and communication between the patients and medical staff, an Android-based mobile app was developed for patients in the LTSC. The app consisted of six functions: general guides for patients admitted to the LTSC, notice board, symptom questionnaire, vital sign reporting, question and answer (Q\&A), and push reminders. The app was released on March 27, 2020 (Figure 5).

Figure 5. Interface of the mobile app for patients admitted to the LTCS. Q\&A: question and answer.

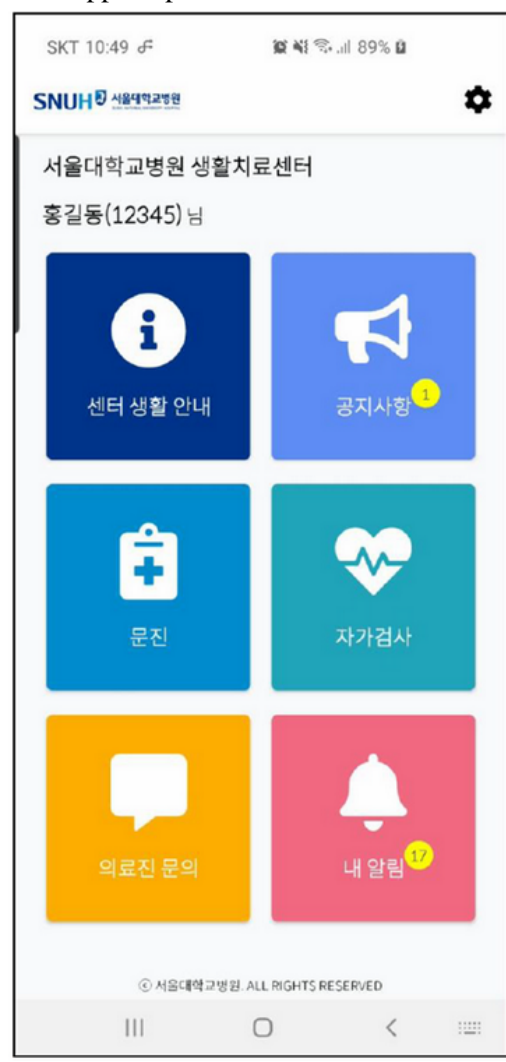

\section{General Guides for the LTSC}

General information on admission to the LTSC and frequently asked questions by patients were organized for patient reference. Administrators could edit or register additional content directly through the app management web portal.

\section{Notice Board}

The notice board was used to send announcements to the patients. A push alarm was triggered when a new announcement was registered.

\section{Symptom Questionnaire}

Patients were asked to self-report their symptoms using the questionnaire in the mobile app. The questionnaire focused on the presence and frequency of symptoms most relevant to COVID-19 (cough, sputum, fever, rhinorrhea, sore throat, dyspnea, and chest pain) but also asked patients to report other more general symptoms (nausea, vomiting, abdominal

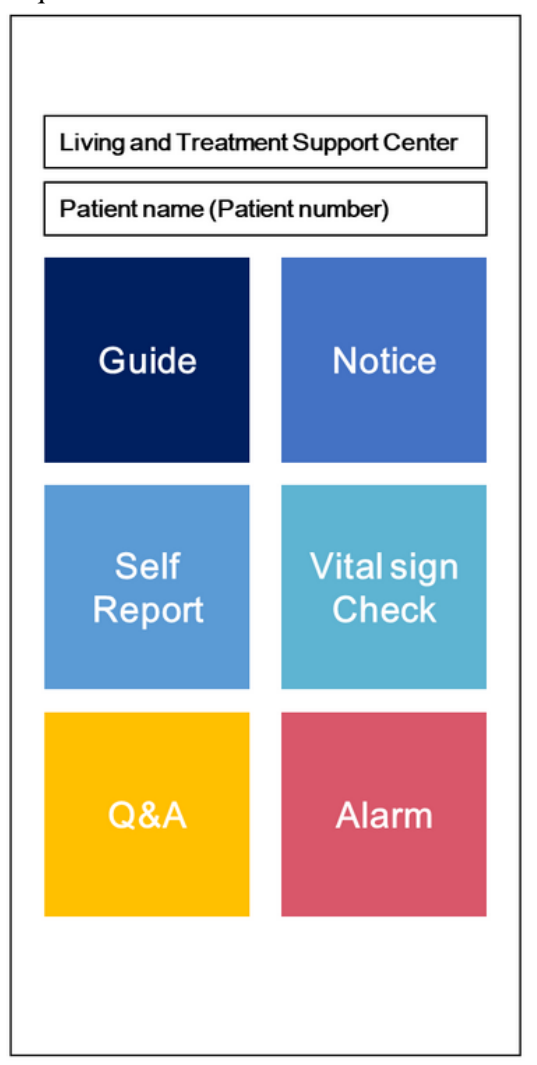

discomfort, constipation, diarrhea, abdominal pain, insomnia, pain, and others). The self-reported data automatically populated the health record template.

\section{Vital Sign Self-Reporting}

In addition to the self-reporting of symptoms, patients were instructed to measure their vital signs twice a day, in the morning and afternoon, with the devices provided in each room and to enter the values into the mobile app. The vital sign measurements were also sent to the HIS to be reviewed by the medical staff.

\section{$Q \& A$}

The Q\&A function was a secure messaging platform for patients to submit questions to the medical team. The staff members replied through the app management web portal, and when a question was answered, a push notification was sent to the patient's mobile phone. 


\section{Push Alarms}

Patients received a push alarm as a reminder to fill out the self-reporting questionnaires for symptoms and vital signs, when their question was answered, or when the medical staff posted a new announcement to the notice board.

\section{Usability Survey}

Twelve patients participated in the online surveys. The mean age of the respondents was 25 years (SD 6.25 years), and 7 $(58 \%)$ were college students. For the mobile app, out of 5 points, the perceived usefulness showed the highest score at 4.62 points (SD 0.48), followed by satisfaction at 4.08 points (SD 1.41) and perceived ease of use at 3.81 points (SD 0.41) (Supplemental Table 1 in Multimedia Appendix 4). When patients rated the experience of using the wearable vital sign monitoring devices out of 5, perceived usefulness scored the highest at 4.45 points (SD 0.57), followed by perceived ease of use at 4.30 points (SD 0.59 ) and satisfaction at 3.98 points (SD 0.70) (Supplemental Table 2 in Multimedia Appendix 4).

A simple satisfaction survey regarding the usability of the mobile app was also conducted with the medical staff. Of the 24 participants who answered the questionnaire, $20(83 \%)$ were nurses and $4(17 \%)$ were physicians. The overall satisfaction score for the mobile app out of five points was 4.10 (SD 0.64) (Supplemental Table 1 in Multimedia Appendix 4).

\section{Discussion}

\section{Principal Findings}

The ICT-based patient management system introduced in this study was applied to the LTSC for clinically healthy COVID-19 patients operated by SNUH. Due to the infectious nature of the disease, it was difficult for medical staff to directly perform patient care; therefore, noncontact management was essential. SNUH introduced an ICT-based care system for the management of clinically healthy COVID-19 patients at the LTSC that fit the entire care flow, from preadmission and admission to discharge or transfer. The process started on March 1, 2020, and was completed in 4 weeks. Korea's strategy of aggressive mitigation through early detection based on extensive diagnostic testing thorough epidemiological investigation and transparent management of COVID-19-related information has "flattened the curve" of the rate of infection [7]. The Ministry of Health and Welfare of Korea has tailored treatment policies and guidelines to match the disease profile of COVID-19 and the available medical resources. As part of their multifaceted approach to COVID-19, the Ministry relaxed regulations and temporarily approved the limited use of telemedicine and e-prescriptions [9]. Because direct telemedicine visits between health care professionals and patients were previously prohibited, the infrastructure and ecosystem around telemedicine were not fully developed [16]. Another approach was the decision to isolate patients with mild symptoms in designated LTSCs from March 1, 2020 [9]. The LTSCs were public or private facilities that were modified to accommodate and quarantine patients. SNUH, as a national hospital of Korea, was also asked to operate an LTSC at the SNUH Human Resources Development Center in Mungyeong. Most of the medical staff were located in the central monitoring center in Seoul and led patient care using telemedicine tools; meanwhile, some staff worked at the Mungyeong site in supportive roles and in preparation for emergencies.

The authors recognized the importance of a multidisciplinary approach to develop a system to support patient care and management at LTSCs as quickly as possible [17-19]. The Office of Hospital Information of SNUH, composed of several medical faculty members, nurses, pharmacists, medical record technicians, and IT experts, manages the IT services of the hospital and was well placed to lead this effort. Moreover, ezCaretech, the company that developed our HIS, is under contract to maintain the HIS and has a team located at SNUH; this team could make timely improvements to the system in a straightforward manner. In addition, HealthConnect, a health care application development company, has been working on a mobile app with SNUH for a project to collect patient-reported outcomes and enable viewing of the data in the HIS. This familiarity with the hospital interfaces and data structures enabled rapid development and deployment of the LTSC app.

\section{Role of Health Care Information Exchange in the Pandemic Era}

Health care information exchange between health care institutions plays an important role during pandemics and disasters [20-24]. In Korea, where the population has high accessibility to health care resources due to the national health insurance program, any patient can visit any hospital. Health records are fragmented among the health care institutions that the patient visits, as the EHR systems used by each institution are different and most are not interoperable [25]. To alleviate this problem, the Ministry of Health and Welfare initiated a nationwide healthcare information exchange (HIE) project in 2017. This service electronically and securely sends and receives medical records and image data of patients who have consented to provide personal information to medical institutions for patient care [26]. However, in the current HIE system, electronic information is generated only when the patient is referred to another medical institution; thus, it is difficult to use it in this situation. Furthermore, the project is not gaining traction as expected due to the cost burden to small and medium-sized hospitals to connect their EHRs with the national HIE system as well as the conflict between health care institutions and the government on reimbursement and penalty policies [27]. As most institutions were not prepared to share image data through the national HIE system, we developed a simple cloud-based image sharing platform to enable efficient exchange. This platform was immediately used for a 55-year-old woman who had no underlying disease and no symptoms at initial presentation but who progressed to pneumonia 3 days after admission. Her physician decided to transfer her to a local general hospital and shared her chest x-ray images through this system.

\section{Lessons From the MERS Outbreak and Application for COVID-19 in South Korea}

South Korea learned important lessons from its 2015 Middle East respiratory syndrome (MERS) outbreak, including the importance of increased transparency, early detection, and rapid 
diagnosis [28-30]. The Korea Centers for Disease Control and the Health Insurance Review \& Assessment Service developed the international traveler information system and provides the service to all health care institutions in Korea [31]. When the patient has visited countries that are being screened, the international traveler information system sends out a real time alert to allow staff to recognize and prevent possible exposure. Similarly, to minimize exposure, the system was used to inform the physician or nurse whether the patient was arriving from the epicenter of the COVID-19 epidemic in Korea, Daegu and Gyeongsangbuk Province, since February 18, 2020.

Although the current pandemic is ongoing, we should also learn from this experience. Telemedicine is ideal for proper triage, early diagnosis, isolation, and treatment of patients [32]. Even in the United States, where access to telemedicine services, coverage, and reimbursement is available, telemedicine use is relatively uncommon [33]. Telemedicine use is even rarer in Korea, which is one of the few countries where patient-facing telemedicine is explicitly banned [16]. All stakeholders involved, including the government, medical communities, civic groups, and politicians, have different opinions. Some believe that Korea should approach this issue differently from other countries due to the nature of the medical system in Korea, which has excellent accessibility and low costs [34]. However, to limit community transmission during the COVID-19 pandemic, the Ministry of Health and Welfare has temporarily approved the limited use of telemedicine with e-prescriptions [9]. With recent studies reporting the advantages of proactive use of IT systems and strategies in infectious patients [35-37], we hope that this experience provides an impetus for the stakeholders of the health care system to improve and expand on the use and application of ICT in health care.

\section{Conclusions}

Faced with a novel infectious disease, we describe the implementation and experience of applying an ICT-based patient management system in the LTSC by SNUH. ICT-based tools and applications are increasingly gaining importance in health care, and we hope that our experience can provide insight into future technology-based infectious disease responses.

\section{Acknowledgments}

We would like to gratefully acknowledge our excellent team members, Suhyeon Kim, Jisu Ha, Buri Lee, and Sanghee Lim from the Hospital Information Development team, Myeonghee Song and Gyeongran Hong from the Medical Records team, Taewoo Kim and Donggyu Lee from the Hospital Information Strategy team, and Hyesook Lee from the Hospital Information System and Security team for their profound dedication and excellence. We would like to thank our colleagues Hyuck Kim from HealthConnect, Jinmo Kim and Sanghak Lee from Tribell Labs, and the IT specialists from ezCaretech. Above all, we would like to express deep gratitude to all experts and volunteers who are still fighting COVID-19. This research was supported by a grant of the Korea Health Technology R\&D Project through the Korea Health Industry Development Institute, funded by the Ministry of Health and Welfare, South Korea (grant number: HI19C0790).

\section{Authors' Contributions}

KHK had full access to all the data in the study and takes responsibility for the integrity of the data and the accuracy of the data analysis. YSB, KHK, CWJ, BC, MSK, and EK conceived and designed the study. YSB acquired, analyzed, and interpreted the data. YSB, SWC, and TK drafted the manuscript. Critical revision of the manuscript was provided by YSB and SWC. YSB and KHK provided administrative, technical, or material support.

\section{Conflicts of Interest}

None declared.

\section{Multimedia Appendix 1}

Supplemental Figure 1. Wearable vital sign recorder.

[PNG File, 280 KB-Multimedia Appendix 1]

\section{Multimedia Appendix 2}

Supplemental Figure 2. Integration of data from the wearable vital sign device into the SNUH HIS.

[PNG File, $371 \mathrm{~KB}$-Multimedia Appendix 2]

\section{Multimedia Appendix 3}

Supplemental Figure 3. Central vital sign monitoring system. [PNG File, 1485 KB-Multimedia Appendix 3]

\section{Multimedia Appendix 4}

Supplemental Table 1. Survey on perceived usefulness, perceived ease of use, and satisfaction with the mobile app. Supplemental Table 2. Survey on perceived usefulness, perceived ease of use, and satisfaction with wearable devices by patients in the LTSC. 
[DOCX File, 17 KB-Multimedia Appendix 4]

\section{References}

1. Paules CI, Marston HD, Fauci AS. Coronavirus Infections-More Than Just the Common Cold. JAMA 2020 Jan 23:Preprint. [doi: 10.1001/jama.2020.0757] [Medline: $\underline{31971553]}$

2. Kim D, Choe YJ, Jeong J. Understanding and Interpretation of Case Fatality Rate of Coronavirus Disease 2019. J Korean Med Sci 2020 Mar 30;35(12):e137 [FREE Full text] [doi: 10.3346/jkms.2020.35.e137] [Medline: 32233163]

3. Lipsitch M, Swerdlow DL, Finelli L. Defining the Epidemiology of Covid-19 - Studies Needed. N Engl J Med 2020 Mar 26;382(13):1194-1196. [doi: 10.1056/nejmp2002125]

4. Guan W, Ni Z, Hu Y, Liang W, Ou C, He J, China Medical Treatment Expert Group for Covid-19. Clinical Characteristics of Coronavirus Disease 2019 in China. N Engl J Med 2020 Apr 30;382(18):1708-1720 [FREE Full text] [doi: 10.1056/NEJMoa2002032] [Medline: 32109013]

5. Korea Centers for Disease Control. Global Locations with COVID-19 URL: http://ncov.mohw.go.kr/en/bdBoardList. do?brdId=16\&brdGubun=163\&dataGubun=\&ncvContSeq=\&contSeq=\&board id=\&gubun= [accessed 2020-03-28]

6. World Health Organization. Coronavirus disease (COVID-2019) situation reports URL: https://www.who.int/emergencies/ diseases/novel-coronavirus-2019/situation-reports [accessed 2020-06-05]

7. Korea Centers for Disease Control. Coronavirus Disease-19, Republic of Korea URL: http://ncov.mohw.go.kr/en/ [accessed 2020-06-05]

8. Korean Society of Infectious Diseases, Korean Society of Pediatric Infectious Diseases, Korean Society of Epidemiology, Korean Society for Antimicrobial Therapy, Korean Society for Healthcare-associated Infection Control and Prevention, Korea Centers for Disease Control and Prevention. Report on the Epidemiological Features of Coronavirus Disease 2019 (COVID-19) Outbreak in the Republic of Korea from January 19 to March 2, 2020. J Korean Med Sci 2020 Mar 16;35(10):e112 [FREE Full text] [doi: 10.3346/jkms.2020.35.e112] [Medline: 32174069]

9. Ministry of Health and Welfare, Republic of Korea. 2020 Mar 09. Current Status of Response to COVID-19 and Future Plans URL: http://www.mofa.go.kr/viewer/skin/doc.html?fn=2020052006593622\&rs=/viewer/result/202006 [accessed 2020-06-05]

10. Hick JL, Biddinger PD. Novel Coronavirus and Old Lessons — Preparing the Health System for the Pandemic. N Engl J Med 2020 May 14;382(20):e55. [doi: 10.1056/nejmp2005118]

11. Yoo S, Lee KH, Lee HJ, Ha K, Lim C, Chin HJ, et al. Seoul National University Bundang Hospital's Electronic System for Total Care. Healthc Inform Res 2012 Jun;18(2):145-152 [FREE Full text] [doi: 10.4258/hir.2012.18.2.145] [Medline: 22844650]

12. Ministry of Health and Welfare, Republic of Korea. 2020 Feb 04. Updates on COVID-19 in Republic of Korea (as of 20 April) URL: http://ncov.mohw.go.kr/en/tcmBoardView.

do?brdId=12\&brdGubun=125\&dataGubun=\&ncvContSeq=1974\&contSeq=1974\&board_id=\&gubun= [accessed 2020-06-05]

13. Deshmukh V, Tripathi S, Patil A, Tripathy J. ScienceOpen Preprints. 2020 May 08. COVID-19 diagnostic multiplicity and its role in community surveillance and control URL: https://www.scienceopen.com/hosted-document?doi=10.14293/ S2199-1006.1.SOR-.PPA94RC.v1 [accessed 2020-06-05]

14. Hong K, Lee S, Kim T, Huh H, Lee J, Kim S, et al. Guidelines for Laboratory Diagnosis of Coronavirus Disease 2019 (COVID-19) in Korea. Ann Lab Med 2020 Sep;40(5):351-360 [FREE Full text] [doi: 10.3343/alm.2020.40.5.351] [Medline: 32237288]

15. Korea Health Insurance Review and Assessment Service. 2020. COVID-19 Living and Treatment Support Center guidelines for medical reimbursement criteria and how to request it. Webpage in Korean URL: http://www.hira.or.kr/bbsDummy. do?pgmid=HIRAA020002000100\&brdScnBltNo=4\&brdBltNo=7876 [accessed 2020-04-03]

16. Oh J, Park Y, Jo EC, Kim S. Current Status and Progress of Telemedicine in Korea and Other Countries. Healthc Inform Res 2015 Oct;21(4):239-243 [FREE Full text] [doi: 10.4258/hir.2015.21.4.239] [Medline: 26618029]

17. Del Rio C, Malani PN. COVID-19-New Insights on a Rapidly Changing Epidemic. JAMA 2020 Feb 28:Preprint. [doi: 10.1001/jama.2020.3072] [Medline: 32108857]

18. Wu Z, McGoogan JM. Characteristics of and Important Lessons From the Coronavirus Disease 2019 (COVID-19) Outbreak in China: Summary of a Report of 72314 Cases From the Chinese Center for Disease Control and Prevention. JAMA 2020 Feb 24:Preprint. [doi: 10.1001/jama.2020.2648] [Medline: 32091533]

19. Wang CJ, Ng CY, Brook RH. Response to COVID-19 in Taiwan: Big Data Analytics, New Technology, and Proactive Testing. JAMA 2020 Mar 03:Preprint. [doi: 10.1001/jama.2020.3151] [Medline: 32125371]

20. Lurie N, Dausey DJ, Knighton T, Moore M, Zakowski S, Deyton L. Community Planning for Pandemic Influenza: Lessons From the VA Health Care System. Disaster Med Public Health Prep 2013 Apr 08;2(4):251-257. [doi:

10.1097/dmp.0b013e31817dd143]

21. Boyd T, Savel T, Kesarinath G, Lee B, Stinn J. The Use of Public Health Grid Technology in the United States Centers for Disease Control and Prevention H1N1 Pandemic Response. 2010 Jan 01 Presented at: 24th IEEE International Conference on Advanced Information Networking and Applications Workshops; April 10-23, 2010; Perth, Western Australia. [doi: 10.1109/waina.2010.60] 
22. Martin R, Conseil A. Public health policy and law for pandemic influenza: a case for European harmonization? J Health Polit Policy Law 2012 Dec;37(6):1091-1110. [doi: 10.1215/03616878-1813854] [Medline: 22899835]

23. Hammond WE, Bailey C, Boucher P, Spohr M, Whitaker P. Connecting information to improve health. Health Aff (Millwood) 2010 Feb;29(2):284-288. [doi: 10.1377/hlthaff.2009.0903] [Medline: 20348075]

24. Han SH, Lee MH, Kim SG, Jeong JY, Lee BN, Choi MS, et al. Implementation of Medical Information Exchange System Based on EHR Standard. Healthc Inform Res 2010 Dec;16(4):281-289 [FREE Full text] [doi: 10.4258/hir.2010.16.4.281] [Medline: 21818447]

25. Moon TJ. Light and Shadows of the Korean Healthcare System. J Korean Med Sci 2012;27(Suppl):S3. [doi: 10.3346/jkms.2012.27.s.s3]

26. Korea Social Security Information Service. 2019 Apr 01. Healthcare Information Exchange. Webpage in Korean URL: http://www.ssis.or.kr/lay1/S1T760C797/contents.do [accessed 2020-06-08]

27. Choi S. Korea Doctor's News. 2019 Aug 07. Korea medical association requests that the hospital information exchange project be discontinued without assistance. Article in Korean URL: https://www.doctorsnews.co.kr/news/articleView.

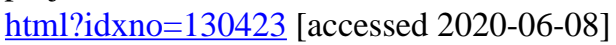

28. Petersen E, Hui DS, Perlman S, Zumla A. Middle East Respiratory Syndrome - advancing the public health and research agenda on MERS - lessons from the South Korea outbreak. Int J Infect Dis 2015 Jul;36:54-55 [FREE Full text] [doi: 10.1016/j.ijid.2015.06.004] [Medline: 26072036]

29. Khan A, Farooqui A, Guan Y, Kelvin DJ. Lessons to learn from MERS-CoV outbreak in South Korea. J Infect Dev Ctries 2015 Jul 04;9(6):543-546 [FREE Full text] [doi: 10.3855/jidc.7278] [Medline: 26142661]

30. Lim P. Middle East respiratory syndrome (MERS) in Asia: lessons gleaned from the South Korean outbreak. Trans R Soc Trop Med Hyg 2015 Sep;109(9):541-542 [FREE Full text] [doi: 10.1093/trstmh/trv064] [Medline: 26286944]

31. Korea Centers for Disease Control. 2018 Sep 28. International Traveler Information System (ITS) URL: http://www. cdc.go.kr/gallery.es?mid=a20503010000\&bid=0002\&act=view\&list no=140757 [accessed 2020-06-08]

32. Ohannessian R, Duong TA, Odone A. Global Telemedicine Implementation and Integration Within Health Systems to Fight the COVID-19 Pandemic: A Call to Action. JMIR Public Health Surveill 2020 Apr 02;6(2):e18810 [FREE Full text] [doi: $10.2196 / 18810]$ [Medline: $\underline{\text { 32238336] }}$

33. Barnett ML, Ray KN, Souza J, Mehrotra A. Trends in Telemedicine Use in a Large Commercially Insured Population, 2005-2017. JAMA 2018 Nov 27;320(20):2147-2149 [FREE Full text] [doi: 10.1001/jama.2018.12354] [Medline: 30480716]

34. Chang H. Evaluation Framework for Telemedicine Using the Logical Framework Approach and a Fishbone Diagram. Healthc Inform Res 2015 Oct;21(4):230-238 [FREE Full text] [doi: 10.4258/hir.2015.21.4.230] [Medline: 26618028]

35. Smith AC, Thomas E, Snoswell CL, Haydon H, Mehrotra A, Clemensen J, et al. Telehealth for global emergencies: Implications for coronavirus disease 2019 (COVID-19). J Telemed Telecare 2020 Mar 20:1357633X2091656. [doi: $10.1177 / 1357633 \times 20916567]$

36. Greenhalgh T, Wherton J, Shaw S, Morrison C. Video consultations for COVID-19. BMJ 2020 Mar 12;368:m998. [doi: 10.1136/bmj.m998] [Medline: $\underline{\text { 32165352] }}$

37. Arsenault M, Evans B, Karanofsky M, Gardie J, Shulha M. Canadian Family Physician. 2020 Mar 26. Covid 19 - Practising Telemedicine in the pandemic URL: https://www.cfp.ca/news/2020/03/26/3-26-1 [accessed 2020-06-05]

\author{
Abbreviations \\ CMS: central monitoring system \\ COVID-19: coronavirus disease \\ DICOM: Digital Imaging and Communications in Medicine \\ EHR: electronic health record \\ e-prescription: electronic prescription \\ HIE: healthcare information exchange \\ HIS: hospital information system \\ ICT: information and communications technology \\ IT: information technology \\ LTSC: living and treatment support center \\ MERS: Middle East respiratory syndrome \\ PACS: picture archiving and communication system \\ Q\&A: question and answer \\ RT-PCR: real time polymerase-chain reaction \\ SNUH: Seoul National University Hospital
}


Edited by G Eysenbach; submitted 11.05.20; peer-reviewed by HA Park, $R$ Lee, T Jamieson; comments to author 26.05.20; revised version received 02.06.20; accepted 02.06.20; published 12.06.20

Please cite as:

Bae YS, Kim KH, Choi SW, Ko T, Jeong CW, Cho B, Kim MS, Kang E

Information Technology-Based Management of Clinically Healthy COVID-19 Patients: Lessons From a Living and Treatment Support Center Operated by Seoul National University Hospital

J Med Internet Res 2020;22(6):e19938

URL: http://www.jmir.org/2020/6/e19938/

doi: $\underline{10.2196 / 19938}$

PMID: $\underline{32490843}$

(C) Ye Seul Bae, Kyung Hwan Kim, Sae Won Choi, Taehoon Ko, Chang Wook Jeong, BeLong Cho, Min Sun Kim, EunKyo Kang. Originally published in the Journal of Medical Internet Research (http://www.jmir.org), 12.06.2020. This is an open-access article distributed under the terms of the Creative Commons Attribution License (https://creativecommons.org/licenses/by/4.0/), which permits unrestricted use, distribution, and reproduction in any medium, provided the original work, first published in the Journal of Medical Internet Research, is properly cited. The complete bibliographic information, a link to the original publication on http://www.jmir.org/, as well as this copyright and license information must be included. 